\title{
Chico-to-Cairo: \\ Analysis of International Virtual Discussions of Terrorism
}

\author{
By: Adam Irish, PhD \\ airish@csuchico.edu \\ Assistant Professor of Political Science \\ Department of Political Science and Criminal Justice \\ California State University, Chico
}

\begin{abstract}
In a globalized world, bringing international voices into the political science classroom takes on renewed urgency. Whether focusing on the readings included in a syllabus, the learning activities that expose students to other perspectives, or physical travel to a foreign locale, political science classes - especially Comparative Politics and International Relations courses - face the pedagogical obstacle and opportunity of conveying the different political perspectives held diverse groups and states. In this article, I build on prior calls for internationalizing the classroom and develop a videoconference discussion of terrorism between students in Chico, California and Cairo, Egypt. In addition to reviewing my collaboration with faculty in Egypt and the structuring of this discussion activity, I present preand post-surveys from students who attended the international videoconference and those that did not. These surveys reveal that students who attended the conference reported an increased confidence in their knowledge of terrorism as well as a deeper appreciation of international perspectives on terrorism. Based on this study I argue for the creation of a more formal networking opportunities between US-based and foreign-based instructors in order to facilitate the availability of low-cost, international experiences as part of a more inclusive, internationalized classroom.
\end{abstract}


Working Draft for APSA Teaching and Learning Conference, Albuquerque, 2020. Do Not Cite or Circulate Without Authors' Permission.

"I was able to see how the Egyptians view the US' view toward terrorism as Islamophobic, and it was interesting to see how seriously Egypt took the threat of terrorism."

- Student comment following videoconference on terrorism (Fall 2019)

Over the years there have been a number of calls by scholars to internationalize classroom experience (Barber et al. 2007; Lantis, Kille, and Krain 2010; Connell 2016; Robles 1993). These efforts have included a focus three parts of the classroom experience: the syllabus (Leslie 2007; Robles 1993), the learning activities inside and outside of class (Mendeloff and Shaw 2009; Shaw 2016), and study abroad opportunities (Makara and Canon 2019). In this article, I build on the prior literature to design and test out an international discussion of terrorism between students in Chico, California and Cairo, Egypt.

After presenting the argument for internationalizing our classrooms (i.e. accessing nonUS or foreign perspectives), I review how videoconferencing technology has been employed to connect students across borders. Next, I detail how I developed a collaboration with a faculty member in Egypt and co-designed a discussion opportunity for our classes. Then I review preand post-surveys given to students in my Introduction to International Relations classes who both attended and did not attend the international videoconference discussion. ${ }^{1}$ Lastly, I argue for the creation of a more formal networking opportunities between US-based and foreign-

\footnotetext{
${ }^{1}$ The alternative time of the discussion (8AM in the morning before the 10 and $11 \mathrm{AM}$ class time) meant that only some of the students in my Intro to International Relations were able to attend the discussion. The remaining students attended class where we discussed the same readings.
} 
Working Draft for APSA Teaching and Learning Conference, Albuquerque, 2020. Do Not Cite or Circulate Without Authors' Permission.

based instructors in order to facilitate the availability of low-cost, international experiences as part of a more inclusive, internationalized classroom.

\section{Why Build an International Political Science Classroom?}

The push to internationalize the political science classroom has repeatedly appeared on the American Political Science Association's Teaching and Learning Conference (APSA-TLC) tracks (e.g. Hudak, Sachleben, and Ward 2011; Mealy 2014) and spawned several lines of pedagogical research into the effects of studying abroad, the inclusion of diverse texts on syllabi, and learning activities that bring students together across borders. This internationalizing has also extended to call for greater faculty collaboration. As Breuning notes in her analysis of the international relations of APSA, "fostering international collaboration by scholars at primarily undergraduate institution will have a direct impact on the education the students who enroll at such institutions receive. It will encourage the internationalization of the curricular and intersect with efforts to build student competences for living and working in a multicultural and globalized world" (2005, 161; Gurin et al. 2002).

But what is an internationalized classroom and why is it so desirable? At its most intuitive level an international classroom is one which includes international reflections of political life. The 2014 APSA-TLC Conference and Track Summaries recounts a survey of definitions for an internationalized curriculum, highlighting the need for "(1) non-US perspectives, materials, authors, and cases; (2) exploring international connections in modern society; and (3) student exposure to other cultures and languages" (Mealy 2014, 723). Some of these definitional requirements are tall order. Languages, for example, take multiple semesters 
Working Draft for APSA Teaching and Learning Conference, Albuquerque, 2020. Do Not Cite or Circulate Without Authors' Permission.

to learn and may require compromises in terms of the number of substantive classes required by a major. Exposure to a foreign culture is best achieved through study abroad, but even advocates note the relative rarity of study abroad experiences for most students (Ungar 2016).

For most US-based instructors, internationalizing their classrooms will mean tracking down studies by foreign scholars, using primary sources from different societies (e.g. protest manifestos, campaign documents, legislative debate records), or cases that highlight key concepts without involving the US (e.g. analyzing nuclear politics via India and Pakistan, rather than the US and Russia). Similarly, connecting to students and their experiences to global systems offer opportunities to introduce foreign perspectives (e.g. film clips of Malaysian protesters and government refusing plastic waste). ${ }^{2}$ In graduate school I regularly assisted a IR class that used the Rolling Stone article "The Man Who Took My Job" to generate discussion of how NAFTA affected workers' lives in both the US and Mexico - thankfully highlighting their common humanity along the way (Baum 2000).

The most frequently cited advantages of the extra effort involved to find and implement non-US materials is that it prepares students for a multicultural workplace and globalized economy (Barber et al. 2007; Breuning 2005). Beyond pure professional preparation, an international classroom can also make our classes more engaging and increase the quality of student scholarship. When not oversimplified or needlessly denigrated, societal and cultural differences are inherently interesting for students. They want to know how other people live and what it is like to navigate different societies. Moreover, confronting and conversing with

\footnotetext{
${ }^{2}$ See short useable clip from Al Jazeera (English) - https://www.youtube.com/watch?v=avVA95cQ1eY
} 
Working Draft for APSA Teaching and Learning Conference, Albuquerque, 2020. Do Not Cite or Circulate Without Authors' Permission.

Non-US perspectives can provide a basis for discussing the importance of good research practices - including the potential for bias to creep into our analyses.

Yet for all the advantages of including non-US materials and connecting students to modern international politics and the diverse perspectives contained therein, these international voices (whether in film or text) remain monologues not dialogues. There is something special about the warmth of another human voice, of the haltering questions, of excited responses, and confusion over responses being worked through. As Shaw recently observed in a study of student engaging across borders on FaceBook:

"To the extent that faculty can move their students beyond the classroom walls in some way to encounter people from other cultures, they build on the goal of internationalizing the classroom."

Thankfully the internet revolution has provided a means of hosting real-time discussion across borders: videoconferencing.

\section{The Inclusivity of Videoconferencing}

As Martin observed over a decade ago, US college students already spend far more time engaged with digital media (now social media) than reading - a disparity that has only grown in the interim $(2007,117)$. Thus, while internationalizing our classrooms through careful textual analysis may continue to grow more difficult, our students, armed with smartphones and facetiming friends and family, are uniquely well suited to videoconferences. The limited pedagogical literature on videoconferencing in political science classrooms suggests as much. While noting the difficulties raised by the time difference between the University of North Florida and the 
Working Draft for APSA Teaching and Learning Conference, Albuquerque, 2020. Do Not Cite or Circulate Without Authors' Permission.

University of Muenster, Zeiser et al. telling reveal that their own students "are encouraging us to introduce live chats and/or Web cam capabilities" $(2013,478)$.

Martin's initial survey of 19 students found general positive response from a majority of US students using WebCT software to communicate online with students in Ecuador and follow up surveys with other larger classes confirmed this positive reception $(2007,116)$. Zeiser et al. found similarly strong praise for video conferences in their cross-border simulation involving American and Canadian students $(2013,39)$. Notably in Zeiser et al.'s design videoconferences were used for a first “icebreaker" session, an interview with Afghanistan's Ambassador to Canada, and in a debrief session. The majority of the international simulation occurred online via SimPlay and do not appear to have involved online real-time videoconferencing (Zeiser, Fuchs, and Engelkamp 2013, 40).

In another innovative use of videoconferencing, Nowak and Zuidema (2019) facilitated interviews between students and professionals working at or with the European Union (EU). Students in this study endorsed the interviews as "a good way to practice interview and communication skills" (Nowak and Zuidema 2019, 9). Like Zeiser et al., Nowak and Zuidema observed some student frustration with technical difficulties - a seemingly common issue across pedagogical research involving technology. For the most part these complaints read as growing pains for very promising online learning communities. A final commonality worth noting is that in the pedagogical literature thus far videoconferencing has been implemented as a minor part of larger, online course projects. Likely this is due to the coordination cost of collaborating with classes across borders and time zones. For good reason, the faculty involved appear to be trying to get the biggest bang for their temporal buck. 
Working Draft for APSA Teaching and Learning Conference, Albuquerque, 2020. Do Not Cite or Circulate Without Authors' Permission.

Despite the universally warm reception of videoconferencing, remarkably few studies have investigated its independent effects outside of surveying student approval. In the following section, I advance the study of videoconferencing the classroom through perhaps the most easily implemented use of the technology - a cross-national discussion between students on an engaging topic. After describing the collaborative process of planning and co-designing this discussion, I review the pre- and post-survey results for my students who attended the Chico-to-Cairo discussion against students who attend my regular class.

\section{Designing the Chico-to-Cairo Discussion}

I was introduced to my collaborator - Michael Lattanzi (American University in Cairo) by a senior colleague in my department ${ }^{3}$ in January of 2019. We arranged a skype conversation and quickly fell into planning the first pilot discussion between our two classes. Michael's class was more general in orientation - East-West Dialogue: Cross-Cultural Perceptions and Reflections - and my own topic-based review of Introduction to IR. ${ }^{4}$ Thus our planning for the initial pilot session was determined by the material my students would be covering at the time. As it happened, humanitarian intervention fit within the available dates and times that both classes could gather. Michael runs several conferences with other classes throughout the year, most of which are constrained to full classes video chatting. Knowing that we wanted our students to have more opportunity for back and forth, we worked with our respective IT

\footnotetext{
${ }^{3}$ My sincere thanks to Dr. Alan Gibson for facilitating the collaboration that led to this paper.

${ }^{4}$ This course followed Pevehouse and Goldstein's (2016) widely used International Relations textbook.
} 
Working Draft for APSA Teaching and Learning Conference, Albuquerque, 2020. Do Not Cite or Circulate Without Authors' Permission.

departments to set up two conference spaces at both sites. ${ }^{5}$ Additionally, we recruited two other faculty to help moderate (Micheal and I divided ourselves across the two discussions).

Finally, as has been noted by others, the time difference between California and Egypt required that we find a time when both groups of students would be willing to come to campus. With a combination of coffee, juice, and doughnuts, I was able to motivate several students to attend the discussion at $8 \mathrm{AM}$.

Our first piloting of this international discussion surfaced several issues. First, we did not establish a set goal for the discussion beyond reviewing a shared set of readings on humanitarian intervention borrowed from my syllabus and emailed out to the students in Cairo. ${ }^{6}$ This proved to be rather challenging as the students struggled to find common ground on the very meaning of "humanitarian intervention." Some of the US students struggled to understand the skepticism with which Egyptian students viewed intervention. Similarly, the concept was stretched toward the US invasion and occupation which took up much of the conversation time, leaving little opportunity to consider humanitarian interventions overseen by the UN.

When we started to design the Fall 2019 discussion, we consulted with the faculty recruited to help monitor the pilot discussion, gathering their feedback on what they thought

\footnotetext{
${ }^{5}$ At American University in Cairo this was less of an obstacle as they have several such rooms equipped to host videoconferencing through the Zoom platform. At CSU, Chico, this required coordinating with our building IT manager who was able to procure webcams and microphones that were mounted atop two large computer displays (55" and 70") in nearby conference rooms. This arrangement allows each classroom to speak with the other by talking directly to the screen where the image from the distant classroom appears. Additionally, the Zoom platform is able to pick up audio and project it with hardly any lag as people are speaking, allowing for effective and efficient conversation even between two sizable groups.

${ }^{6}$ These readings were abridged versions of classic humanitarian intervention articles included in various editions of Art and Jervis' anthology International Politics: Enduring Concepts and Contemporary Issues - namely, Annan's "Reflections on Intervention"; Western and Pevehouse, "Humanitarian Intervention Comes of Age"; and Benjamin Valentino, "The True Costs of Humanitarian Intervention".
} 
Working Draft for APSA Teaching and Learning Conference, Albuquerque, 2020. Do Not Cite or Circulate Without Authors' Permission.

went well and what could be improved. Over an exchange of emails and then a fairly lengthy Skype conversation, we decided that we would place some minimal guideposts on the discussion and would each speak with our respective students about cultivating productive exchanges. Though my initial concern was that US students were, at times, being pushed to defend US policy, many reported being very interested in the discussion. I also learned from Michael that many of his students believed US students were perhaps more able to affect political change in US policy. In both cases, our open and honest communication as collaborators was essential to building an understanding of what we mutually wanted (a freewheeling, productive discussion with a light a touch as possible) and our students needed (discussion guideposts and some discussion of expectations to clarify the point of engaging in an international discussion).

Lastly, for the recent iteration of Chico-to-Cairo, we opted to shift the discussion topic to terrorism. In part this was driven by the needs of my introductory course, but it also reflected the resurgent relevance of US policy shifts toward the Islamic State. Terrorism presents a number of definitional obstacles capable of producing a conversational quagmire. To avoid this fate, Michael opted to discuss the readings we agreed to use ${ }^{7}$ with his students in advance and I presented some contextual evidence about terrorism as a global phenomenon - much of it occurring in Middle East and Asia, despite the coverage given to incidents in western countries. We also agreed upon a set of goals for the discussions: to discuss whether terrorism is definable or not, how we should understand groups often labeled as terrorists, and what, if any, solutions

\footnotetext{
${ }^{7}$ Drawing again from Art and Jervis' anthology International Politics: Enduring Concepts and Contemporary Issues - we used Hoffman's “What is Terrorism?” article alongside Osama bin Ladin's address attempting to justify 9/11.
} 
Working Draft for APSA Teaching and Learning Conference, Albuquerque, 2020. Do Not Cite or Circulate Without Authors' Permission.

might be available for policy makers. Ultimately, our goal was for students to discuss different aspects of terrorism as a way to confront different perspectives within and between the two groups of students.

Prior to any discussion of terrorism in my class, I offered extra credit for completing a survey on terrorism (see Appendix A). This survey covered student knowledge and interest in the topic of terrorism. Most importantly, the survey asked student to describe what they understood to be the perspectives of the US, Middle East, and terrorist groups. It also inquired about their belief in the top three best solutions and why those solutions should be tried. $A$ week after students attended either the Chico-to-Cairo discussion the same survey was offered again with an additional question ${ }^{8}$ about how the student felt class or the Chico-to-Cairo experience affected their understanding of terrorism.

Of 77 students enrolled across two classes, 18 attended the Chico-to-Cairo discussion instead of the regular class session covering terrorism. These students were divided equally between each class and mirrored the classes composition in terms of year in college and gender. I gathered a total of 109 pre- and post-survey responses. Because both surveys run in Blackboard were anonymous there is no way to compare the individual pre- and post-survey scores of individual students. Group statistics can still be compared, as can the perspective taking answers of students that attended the Chico-to-Cairo versus the regular class. Of 60 post-survey responses, 53 included perspective taking answers - 16 from Chico-to-Cairo attendees and 37 from students that attended class.

\footnotetext{
8 This additional question was asked at the end of the survey to avoid forcing students toward reflecting on their class or Chico-to-Cairo experience rather than offering their beliefs about US, Middle Eastern, and terrorist group views.
} 
Working Draft for APSA Teaching and Learning Conference, Albuquerque, 2020. Do Not Cite or Circulate Without Authors' Permission.

In both instances, students completed a 10-question quiz on the readings before class and the Chico-to-Cairo discussion to ensure that they had read and understood the key parts of each reading. ${ }^{9}$ Both the regular class and the international discussion lasted one hour.

The regular class (my control group) discussed that same three elements of terrorism (definability, understanding groups labeled at terrorists, and potential solutions). I did attempt to interject the dangers of stereotyping into this discussion by having students review Reza Aslan's famous exchange with CNN about "Muslim countries." ${ }^{10}$ In addition to this clip, I also showed student world maps measuring the impact of terrorism ${ }^{11}$ and state fragility. ${ }^{12}$ Visually there is significant overlap in each map, demonstrating the well-documented correlation between fragile states suffering the worst impacts of terrorism. Although neither the film clip nor the maps bring an international voice into the classroom, they were intended to raise the risk of thinking of Middle Eastern states as monolithic or of terrorism as defined by attacks on western states. Thus, I have done as much as I could within the confines of introductory class session to promote critical thinking of a difficult topic. The students in both the class and the Chico-to-Cairo readily engaged in discussion of the topic and spent roughly similar amounts of each hour on each topic - in both cases tilting heavily toward definitional discussions.

Based on the prior year's piloting of the Chico-to-Cairo discussion and recent social psychological research (Pauker et al. 2018), my expectations were that students who participated in the Chico-to-Cairo discussion would describe the Middle East's perspective on

\footnotetext{
${ }^{9}$ These quizzes could be retaken a number of times and identified which responses were incorrect after each attempt. By the day that class and the Chico-to-Cairo discussion happened, every student across the two classes had successfully completed the quiz with a score of 10/10.

10 https://www.youtube.com/watch?v=2pjxPR36qFU

${ }_{11}$ Drawn from the Global Terrorism Index (Institute for Economics and Peace).

12 Drawn from the Fragile States Index (Fund For Peace).
} 
Working Draft for APSA Teaching and Learning Conference, Albuquerque, 2020. Do Not Cite or Circulate Without Authors' Permission.

terrorism in more nuanced ways. Similarly, I expected these students to describe the US's

perspective on terrorism in more critical terms (i.e. pointing out a lack of perspective or placing the US in a less hegemonic position visavi terrorism). I did not expect students to vary much on how they describe terrorist groups' perspectives. ${ }^{13}$ Lastly, students who attend Chico-to-Cairo should be less likely to list military solutions to terrorism.

\section{Results}

Comparing the pre- and post-surveys, a statistically significant increase appeared in the students' self-report of their knowledge of terrorism. This increase is evident whether the students attended the regular class or the Chico-to-Cairo discussion. There was no similar increase in either groups' reported interest in the topic of terrorism. Similarly, there does not appear to be any correlation between a student's year, number of prior IR classes, or GPA and self-reported knowledge level or interest in terrorism. Given the diversity of students and their interests in the typical introductory IR class, these results are not particularly surprising. Students appear to have (on average) gained some confidence in their knowledge of the subject, as we should expect they would from having them read about terrorism and then discuss it for an hour.

However, when we turn our attention to the perspective taking questions, a different set of results presents themselves. These questions asked students to "Please describe what

\footnotetext{
${ }^{13}$ Aside from bin Laden's justification for 9/11, the terrorist perspective as left largely unvoiced. No one in either group of the discussion I monitored sought to defend terrorist groups as freedom fighters or as pushed to action by broader systemic power structures. Similarly, Michael did not report any students defending or taking a position that could be ascribe as supporting a terrorist group's perspective.
} 
Working Draft for APSA Teaching and Learning Conference, Albuquerque, 2020. Do Not Cite or Circulate Without Authors' Permission.

you believe to be 's perspective on terrorism," with the blank section filled in by

one of three options: The United States, the Middle East region, or terrorist organizations (e.g.

Al Qaeda, ISIS, the Irish Republican Army).

The first, and most striking, element of the student responses is the variation in their length. In all instances but the terrorist perspective question, the average response length of students that attended Chico-to-Cairo was much longer.

Table 1

Average Word Count of Student Responses

\begin{tabular}{l|c|c|c|c}
\hline & US Perspective & $\begin{array}{l}\text { Middle East Region } \\
\text { Perspective }\end{array}$ & $\begin{array}{l}\text { Terrorist Group } \\
\text { Perspective }\end{array}$ & $\begin{array}{l}\text { Self-report of } \\
\text { Class/C2C Effect }\end{array}$ \\
\hline Attended Chico-to-Cairo & 96 & 72 & 55 & 82 \\
\hline Attended Class & 37 & 35 & 35 & 22 \\
\hline
\end{tabular}

The responses from students that attended class tended to focus on the film clip shown, map comparisons, global power politics or, alternatively, personal beliefs, often written with a strong first-person voice. In contrast, students that attended the Chico-to-Cairo discussion tended to comment on moments during the discussion and engaged more readily in taking the perspective of others.

"I think the Middle East region sees diplomacy as not a top priority, and would rather go in militarily before considering other options."

"After our talk with the students in Cairo, their view on terrorism is that it's a pressing matter that needs to be defined so that they can deal with the issue because they live surrounded by the people other countries are afraid of."

The sample comments above capture this tonal shift across the comments made. While a number of students in both groups still made inaccurate statements, there is a notable decrease from the initial pre-survey perspective taking questions. A significant majority of those responses appear to default to common media or film narratives, likely conditioned on 
Working Draft for APSA Teaching and Learning Conference, Albuquerque, 2020. Do Not Cite or Circulate Without Authors' Permission.

the student's political partisanship and viewing habits. This is likely an effect of over $80 \%$ of students reporting only having taken between 0-2 prior political science courses, likely not in the IR subfield.

Breaking down comments by their content reveals additional differences. I reviewed each set of comments for themes that repeated across more than four responses. Themes were dependent on what students say a noteworthy about each perspective and thus vary across the different perspectives. As captured in the charts below, there are fairly stark differences between the responses of students that attended Chico-to-Cairo versus regular class. ${ }^{14}$

Figure 1

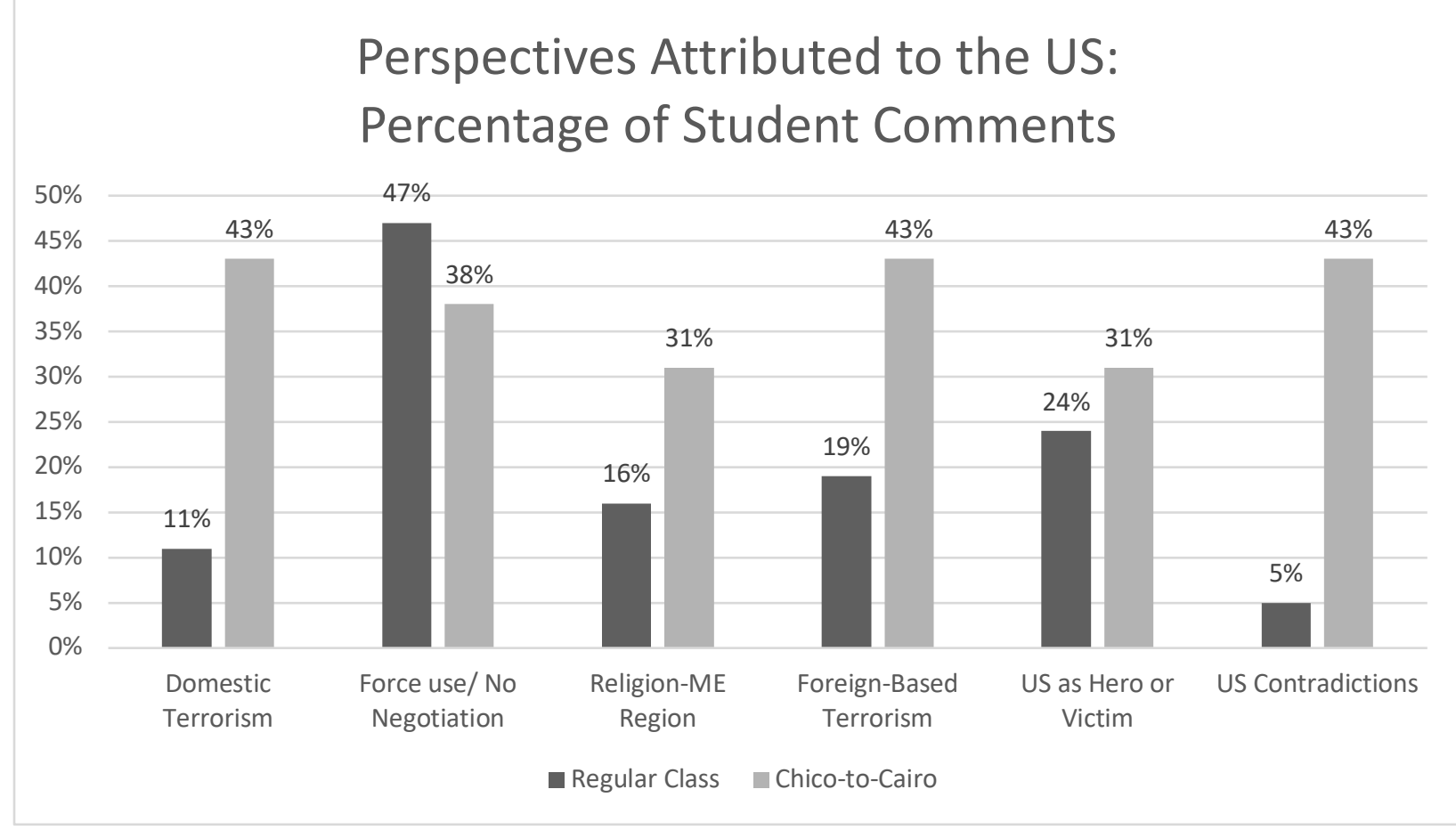

\footnotetext{
${ }^{14}$ Note that given the different response sample sizes (16 and 37), I report the percentage of respondent comments that mention the established theme.
} 
Working Draft for APSA Teaching and Learning Conference, Albuquerque, 2020. Do Not Cite or Circulate Without Authors' Permission.

Figure 1 captures in brief a nuanced difference between the two groups. In the lengthier answers, students who attended the Chico-to-Cairo discussion typically picked up on the difficulty of reconciling the common narrative of foreign-based terrorism that has targeted the US in the past (e.g. 9/11) and domestic shooting incidents. This captures an interesting definitional debate that broke out in both Chico-to-Cairo discussion sections about how to classify mass shootings in the US. Egyptian students were especially interested to ask US students how they thought of these events. Meanwhile, in the regular class discussion this issue was raised but never developed as intensely. Thus, above we see higher rates of mentioning the sources of terrorism, as well as, religion (often framed as commentary on US stereotypes), the US as hero/victim, and contradictions in the US's perspective.

In contrast the regular class responses tended to focus on national security and the US use of force. These types of responses tended to frame the issue as it being necessary for the US to forcefully respond:

"Essentially, I believe that the United States follows the 'speak softly and carry a big stick' policy, meaning diplomacy is always Plan A, but if it fails to go with force."

Equally notable was the presence of unironic comments about $A$ ) the US as a hero in the political dynamic of terrorism or, in some instances, B) comments which focused blame on the Middle East or Islam.

"The United States has a very interactive approach in pursuit of peace and happiness perspective on terrorism. They just want every nation and or country to be a democracy like us. We always take it upon ourselves to be the heroes and intervene."

"The Western media will always portray Muslims as terrorists unless they fix their narrative. 
Working Draft for APSA Teaching and Learning Conference, Albuquerque, 2020. Do Not Cite or Circulate Without Authors' Permission.

In contrast, most comments from Chico-to-Cairo attendees related to religion or region were made to point out either the danger posed by domestic, native born terrorists in contrast to foreigners or the misconception of equating Islam and terrorism.

Figure 2

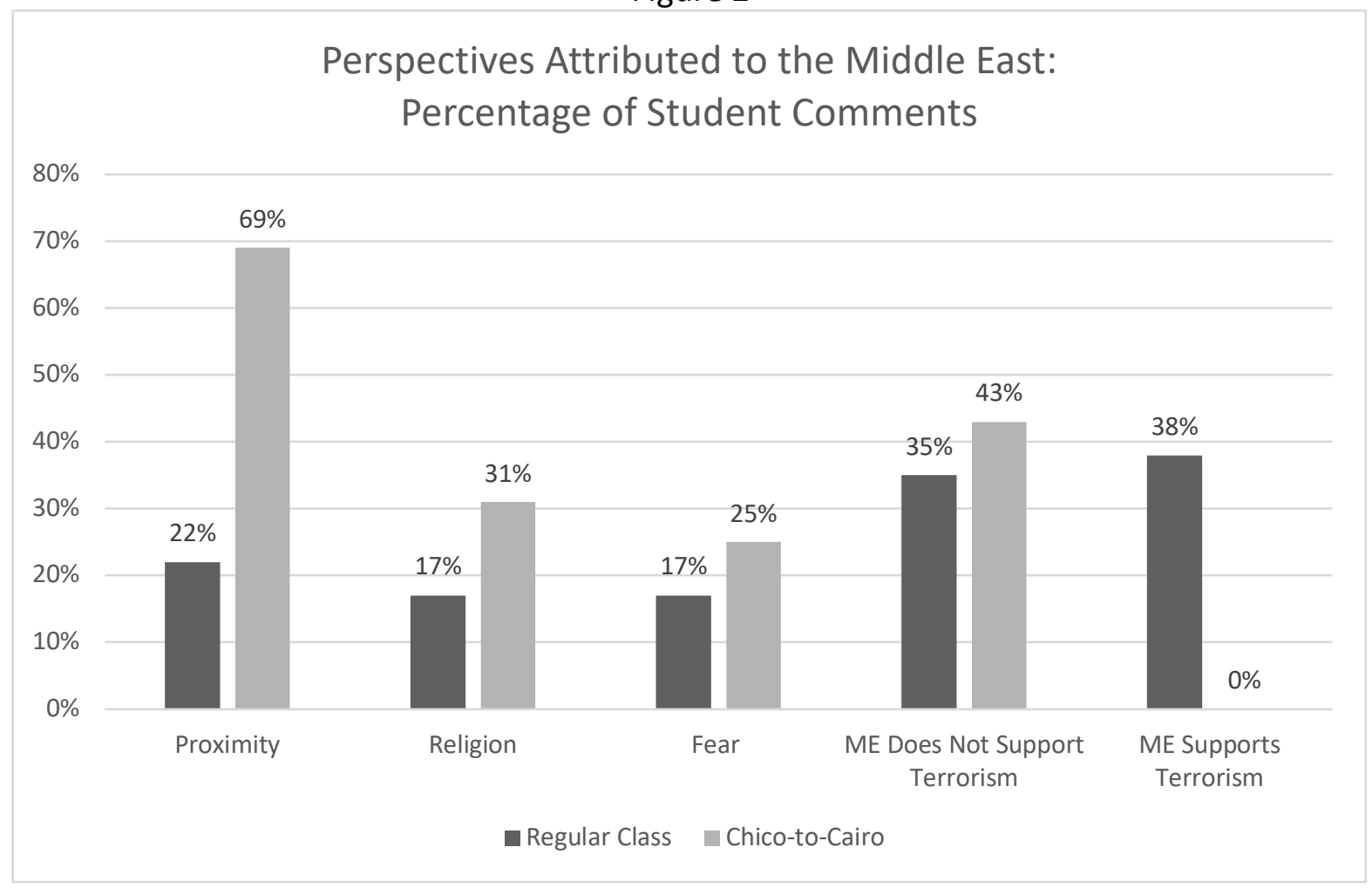

When the focus shifts to the Middle East as a region, student responses show even starker differences. It was in this response section that most of the Chico-to-Cairo attendees related their discussion with the Egyptian students. For example:

"I believe the middle east agrees with that terrorism is; however, after speaking to the people in Cairo, they seem to be even more fearful about it than us. They feel they are surrounded by it. Where Americans make excuses or deny that Americans can be terrorists (i.e. mental illness) they do not believe that. Any act of terrorism constitutes a terrorist."

A majority of these comments focused on the proximity and fear associated with extremist, violent groups. Despite the impact of these exchanges, there was only a minor uptick in the 
Working Draft for APSA Teaching and Learning Conference, Albuquerque, 2020. Do Not Cite or Circulate Without Authors' Permission.

expressed belief that the Middle East as a region doesn't support terrorism. The most striking result was the wholesale absence of expressions that the Middle East may support terrorism among the students that actually spoke with a student living and studying in Cairo. Despite my best efforts to counter stereotypical thinking about Muslim states and empirically highlighting the dangers that terrorism poses to Middle Eastern states, over a third of students that attended class described the Middle East as being supportive of terrorism, in many cases viewing terrorist groups as informal extensions of the state.

"I feel like for the middle east they have a different perspective of terrorism and is something normal for certain groups, organizations, and religions because they grow with different ideologies."

"I believe that the Middle Easts is using terrorism as a driving force to gain influence over the Middle East. Using chaos to overthrow potential threats, but that depends where exactly in the Middle East is specified."

"The middle east wants to perform Terrorism on other countries."

These types of responses are thankfully in the minority but their persistence is troubling. The results above indicate the finding ways to include foreign student voices in the classroom even for a single, one-hour discussion - may provide enough human conversation to activate student empathy for groups and different than their own.

In contrast to the distinctions present in the first two perspective taking questions, when students were asked to state what they believed the terrorist perspective ${ }^{15}$ there was little difference in the responses. Overwhelmingly students emphasized that terrorists used terrorist attacks as a means to an end. Additionally, students often noted the inability of terrorists to affect change politically. Most responses that mentioned religion discussed it as

\footnotetext{
${ }^{15}$ At this point all students had read bin Laden's speech to the US justifying 9/11.
} 
Working Draft for APSA Teaching and Learning Conference, Albuquerque, 2020. Do Not Cite or Circulate Without Authors' Permission.

secondary to the political goals of terrorists. As evidence in the quotes above, the Egyptian students pushed hard in the discussion to both define and condemn the dangers posed by terrorist and extremist religious groups.

Two important inferences can be drawn from the US students' responses. First, given the difference in the immediacy of danger for students in Cairo versus Chico, privilege is at work. Most - likely all - students in Chico are insulated from the actions and violence of extremist groups. Thus, they take a more philosophical view of terrorist attacks as part of political battle, simply fought by different means. It is likely that they would express more conflicted views if they were more immediately faced with the prospect of terrorist violence.

Second, these responses suggest that the inclusion of bin Laden's speech justifying 9/11 appears to have given students enough of a perspective to blunt knee jerk rejections of terrorists as crazy or irrational. Most students wrestled with bin Laden's historical allusions and several students from both groups followed up with me in office hours with questions about US interventions abroad. Although this is promising news for internationalizing the classroom, I remain uncertain about whether or not this internationalized philosophical, historical artifact is the best way help students grasp to gravity of extremism and violence.

Lastly, when surveyed about what solutions they would advocate for as the best options for addressing terrorism students displayed a creative mix of options. 
Working Draft for APSA Teaching and Learning Conference, Albuquerque, 2020. Do Not Cite or Circulate Without Authors' Permission.

Figure 3

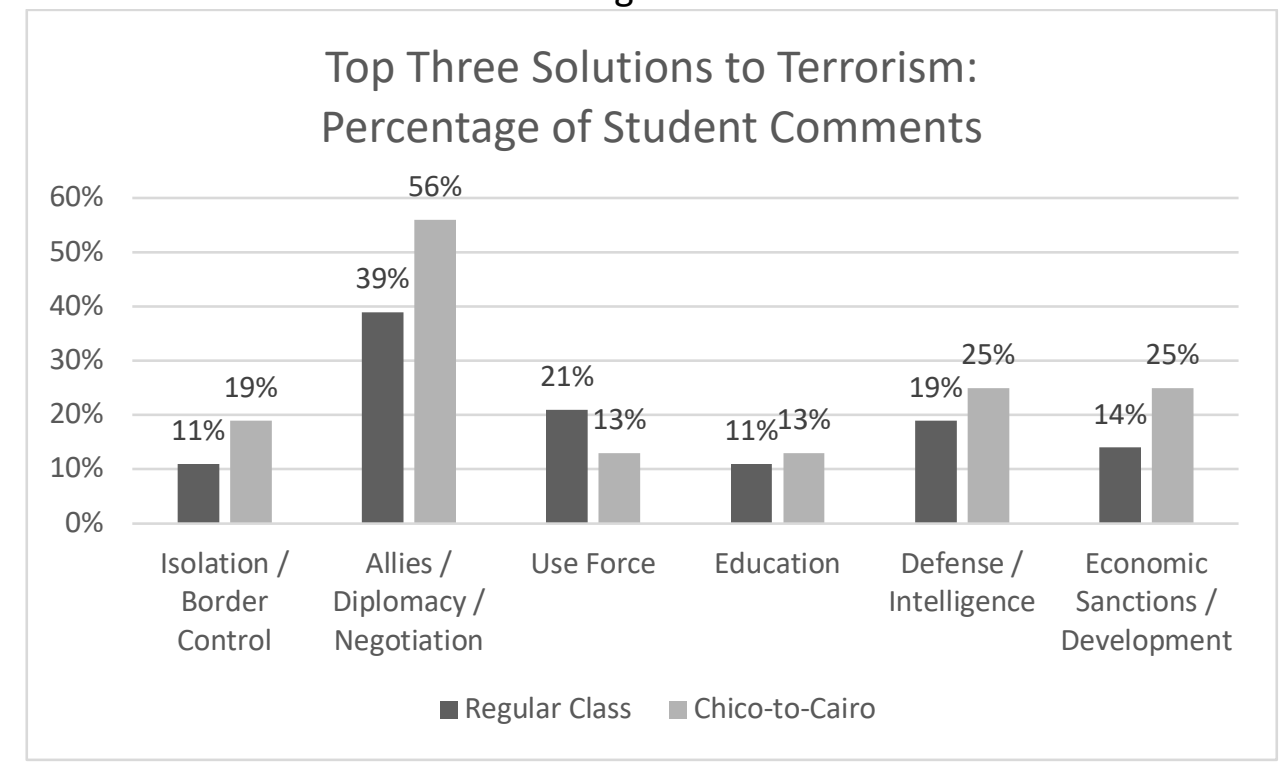

Across both groups, responses advocating the use of force fell from $43 \%$ in pre-survey responses with the students in Chico-to-Cairo favoring other solutions more enthusiastically than students that attended the regular class. In general, these results suggest that any exposure to the realities of terrorism is likely to reduce caviler responses to "nuke" terrorists or even at the possibility of successful countering terrorism with uses of force. ${ }^{16}$ Additionally, several students that attended the Chico-to-Cairo session noted the "overlap" or "similarities" in their concerns and the concerns of the Egyptian students. This may be the root of the large number of responses preferring that diplomacy and alliance be used to counter terrorist groups.

\footnotetext{
${ }^{16}$ Though in both groups there were still a handful of students that reserved their third best solution to terrorism as a literal nuclear option.
} 
Working Draft for APSA Teaching and Learning Conference, Albuquerque, 2020. Do Not Cite or Circulate Without Authors' Permission.

\section{Conclusions}

This study of videoconferencing as a way of including international voices in the classroom provides evidence that international discussion can achieve the following:

- Draw students away from triumphant national narratives to more critical thinking

- Create empathy for students living and studying abroad and counter stereotypical thinking

- Further encourage creative problem solving of global issues

Most promisingly, this study is evidence that with minimal capital investment (i.e. the cost of web-cameras and microphones) and time (e.g. a single hour-long discussion) instructors can create a more inclusive classroom that motivates better, more critical thinking about issues.

As with any teaching experiment, the devil is in the details. The most precarious aspect of this entire project was the good fortune that I had to be introduced to Michael. We have now expanded these international discussions to include another of his colleagues based in Cairo. I am also in the early stages of planning a collaboration with a scholar based in China, who I met through the MPSA faculty mentorship program. Professional networks will ultimately make or break the spread of internationally inclusive classroom practices, like videoconference discussions. Unless someone is situated inside an international network or does, relying individual profession networks will likely expose us only to others in similar institutional types, similar nation-state locations, and similar areas of topical expertise. ${ }^{17}$ Relying on good fortune of the weak ties of our colleagues is at best an inefficient solution for instructors wanting to internationalize their classrooms through actual human interaction. To that end, our

\footnotetext{
${ }^{17}$ My own research focuses on international law and democracy.
} 
Working Draft for APSA Teaching and Learning Conference, Albuquerque, 2020. Do Not Cite or Circulate Without Authors' Permission.

professional organizations - especially those with an international or educational focus, e.g. the International Studies Association, APSA's Education Section - should create networking platforms to connect instructors interested in facilitating an international discussion. These could easily be modeled on existing professional mentorship platforms that match perspective mentors and mentees. Although language barriers and time zone differences will remain consistent obstacles to easy implementation of video conferencing within a designated class meeting time, the above study suggests that, even once a semester, an early morning international videoconference could significantly alter our students' understanding of politics. 
Working Draft for APSA Teaching and Learning Conference, Albuquerque, 2020. Do Not Cite or Circulate Without Authors' Permission.

Bibliography

Barber, Benjamin R. et al. 2007. "Internationalizing the Undergraduate Curriculum." PS: Political Science and Politics 40(1): 105-120.

Baum, Dan. 2000. "The Man Who Took My Job." Rolling Stone (April).

Breuning, Marijke. 2005. "The International Relations of APSA." PS: Political Science \& Politics 38(1): 159-161.

Connell, Christopher. 2016. "The Ascent of Global Learning." International Educator March/April.

Gurin, Patricia, Eric Dey, Sylvia Hurtado, and Gerald Gurin. 2002. "Diversity and Higher Education: Theory and Impact on Educational Outcomes." Harvard educational review 72(3): 330-367.

Hudak, Kristen, Mark Sachleben, and Deborah E. Ward. 2011. "2011 APSA Teaching and Learning Conference Track Summaries: Track: Internationalizing the Curriculum I: InClass and Discipline-Wide Strategies." PS: Political Science \& Politics 44(3): 660-662.

Lantis, Jeffrey S., Kent J. Kille, and Matthew Krain. 2010. “Active Teaching and Learning: The State of the Literature." Oxford Research Encyclopedia of International Studies. https://oxfordre.com/view/10.1093/acrefore/9780190846626.001.0001/acrefore9780190846626-e-427 (February 1, 2020).

Leslie, Isis. 2007. "Internationalizing Political Theory Courses." PS: Political Science \& Politics 40(1): 108-110.

Makara, Michael, and Kinsey Canon. 2019. "More Than a Vacation? Assessing the Impact of a Short-Term Study Abroad Program to the Middle East." Journal of Political Science Education: 1-21.

Martin, Pamela L. 2007. "Global Videoconferencing as a Tool for Internationalizing Our Classrooms." PS: Political Science \& Politics 40(1): 116-117.

Mealy, Kimberly A. 2014. "2014 APSA Teaching and Learning Conference and Track Summaries." PS: Political Science \& Politics 47(3): 711-730.

Mendeloff, David, and Carolyn Shaw. 2009. "Connecting Students Internationally to Explore Postconflict Peacebuilding: An American-Canadian Collaboration." Journal of Political Science Education 5(1): 27-54.

Nowak, Tobias, and Andrew Zuidema. 2019. "Calling Brussels: An Innovative Teaching Project." Journal of Political Science Education: 1-11. 
Working Draft for APSA Teaching and Learning Conference, Albuquerque, 2020. Do Not Cite or Circulate Without Authors' Permission.

Pauker, Kristin et al. 2018. "The Role of Diversity Exposure in Whites' Reduction in Race Essentialism Over Time." Social Psychological and Personality Science 9(8): 944-52.

Pevehouse, Jon C. W., and Joshua S. Goldstein. 2016. International Relations. 11 edition. Boston: Pearson.

Robles, Alfredo C. 1993. “How 'International' Are International Relations Syllabi?” PS: Political Science \& Politics 26(3): 526-528.

Shaw, Carolyn M. 2016. "Connecting Students Cross-Nationally through Facebook." Journal of Political Science Education 12(3): 353-368.

Ungar, Sanford J. 2016. "The Study-Abroad Solution: How to Open the American Mind." Foreign Affairs 95(2): 111-123.

Zeiser, Pamela A., Doris Fuchs, and Stephan Engelkamp. 2013. "Discussions across Borders: A German-American Partnership." Journal of Political Science Education 9(4): 474-486. 
Working Draft for APSA Teaching and Learning Conference, Albuquerque, 2020. Do Not Cite or Circulate Without Authors' Permission.

\section{Appendix A - Pre and Post-Survey Questions}

1. I am very excited to discuss/study terrorism
a) Strongly Agree
b) Agree
c) Neutral
d) Disagree
e) Strongly Disagree

2. Rate your current level of knowledge of both terrorism and possible responses to terrorism.

a) I know a lot about terrorism and I am aware of most of the possible solutions to terrorism.

b) I know some things about terrorism and I am aware of some possible solutions to terrorism.

c) I know very little about terrorism and I am aware of only a few possible solutions to terrorism.

d) I haven't studied terrorism before and have only ever heard about terrorism in passing (e.g. on the news).

3. What year of college are you currently in (by credit)?
a) First-year
b) Second-year
c) Third-year
d) Fourth-year or beyond

4. Which of the following would capture your overall GPA?
a) $0.0-1.0$
b) $1.1-2.0$
c) $2.1-3.0$
d) $3.0-4.0+$

5. How many IR-specific courses have you taken prior to our current class?
a) $0-2$
b) $3-4$
c) $5-6$
d) 7 or more

6. Please describe what you believe to be the United States' perspective on terrorism.

7. Please describe what you believe to be the Middle East region's perspective on terrorism. 
Working Draft for APSA Teaching and Learning Conference, Albuquerque, 2020. Do Not Cite or Circulate Without Authors' Permission.

8. Please describe what you believe to be terrorist organizations' (e.g. Al Qaeda, ISIS, the Irish Republican Army, etc.) perspective on terrorism.

9. Please list and describe what you believe to be the three best solutions to terrorism. For each solution please offer reasons why this solution should be tried.

10. Please note whether you attended class or the Chico-to-Cairo discussion. How do you think class or the Chico-to-Cairo discussion affected your understanding of terrorism and possible responses to terrorism. 